\title{
New approaches to molecular profiling of tissue samples
}

Carolyn J.M. Best ${ }^{\text {a }}$, John W. Gillespie ${ }^{\text {a,c }}$, Chad R. Englert a , Jennifer I. Swalwell ${ }^{\text {a }}$, John Pfeifer ${ }^{b}$, David B. Krizman ${ }^{c, d}$, Emanuel F. Petricoin ${ }^{\mathrm{e}}$, Lance A. Liotta ${ }^{\mathrm{d}}$ and Michael R. Emmert-Buck ${ }^{\text {a,* }}$

${ }^{a}$ Pathogenetics Unit, Laboratory of Pathology, National Cancer Institute, National Institutes of Health, Bethesda, MD, USA

${ }^{\mathrm{b}}$ Center for Information Technology, National Institutes of Health, Bethesda, MD, USA

${ }^{\mathrm{c}}$ Cancer Genome Anatomy Project, Advanced Technology Center, National Cancer Institute, Gaithersburg, MD, USA

d Office of the Chief, Laboratory of Pathology, National Cancer Institute, National Institutes of Health, Bethesda, MD, USA

${ }^{\mathrm{e}}$ Division of Cytokine Biology, Center for Biologics and Research, Food and Drug Administration, Bethesda, MD, USA

Received 31 March 2000

Accepted 4 April 2000

Figures on http://www.esacp.org/acp/2000/20-1/best.htm

The past decade has witnessed several technological advances that are having a significant impact on the field of molecular pathology. For example, widespread use of the polymerase chain reaction (PCR) now provides for routine amplification of DNA and mRNA from small amounts of template, exponentially less than was previously needed, allowing for more thorough analyses of nucleic acids. In parallel, several

\footnotetext{
*Correspondencing author: Michael R. Emmert-Buck, M.D., Ph.D., Pathogenetics Unit, Laboratory of Pathology, National Cancer Institute, Building 10, Room 2A33, 9000 Rockville Pike, Bethesda, MD 20892, USA. Tel.: +1 301496 2912; Fax: +1 301594 7582; E-mail: mbuck@helix.nih.gov.
}

high-throughput platforms have been developed that are capable of performing global measurements of cell transcriptomes and proteomes $[1,2,7,10,11,13,26,28$, $29,37,38]$. These methods have the potential to identify individual genes and pathways that are important in both normal cellular physiology and pathology, as well as to determine the patterns of expression that mediate cellular behavior. For studies of tissue samples it is often desirable to selectively procure specific normal or diseased cells from a complex tissue milieu. Studies of this type are being advanced by several new tissue microdissection methods. Taken together, these technical advances have the potential to greatly improve our understanding of the molecular profiles that underlie normal cellular physiology and disease processes in a variety of biological systems.

Our laboratory utilizes a tissue microdissectionbased approach to perform molecular profiling studies of human cancer. The importance of tissue microdissection to molecular pathology research is evident by the fact that therapies targeted to specific cellular abnormalities can be developed only when the responsible molecular alterations are precisely identified and understood. To obtain a clear representation of normal physiology and disease, one must be able to specifically isolate and examine aberrant cells. Tissue microdissection provides for the procurement of specific cell types from a specimen. For example, a pure population of tumor cells can be analyzed without any interference from neighboring non-tumor cells. Additionally, investigators can recover select sub-populations of cells such as those of pre-malignant lesions that cannot be studied in bulk tissue specimens. Several methods of tissue microdissection have been described in the literature $[4,5,15,25,30]$. The most important parameters are speed, precision, and avoidance of contamination, and any method that achieves these to the satisfaction of the dissector is adequate. Our group developed a laser capture microdissection (LCM) system at the 
National Cancer Institute, which greatly increases the speed and efficiency of tissue microdissection $[6,12]$. The system works by placing an ultrathin, transparent, thermoplastic film on top of a routinely prepared tissue section and activating the film with a pulse from a focused laser beam. The laser pulse is very brief (approximately $5 \mathrm{~ms}$ ) and the membrane is activated at $90^{\circ} \mathrm{C}$, resulting in only a brief thermal transient in the tissue. Once the laser has been fired, which can be done at various laser diameters, the activated film adheres tightly to the underlying cell or cells, which are then selectively procured from the tissue section when the film is removed. The laser capture is performed while the investigator observes the tissue through the microscope, thus precise and selective transfer is ensured. In addition, images of tissue and cells can be captured before, during, and after microdissection, which is critical in maintaining an accurate record of each dissection and correlating histopathology with subsequent molecular results. After microdissection is complete, the cells are extracted from the film using an appropriate buffer and the biomolecules recovered for analysis.

Laser capture microdissection is applicable to many types of molecular pathology research, and its development is now providing access to populations of cells that were previously difficult to study. For example, LCM has recently been used to differentiate the genetic profiles of small (less than or equal to $6 \mathrm{~mm}$ ) and large (7-30 $\mathrm{mm}$ ) foci of hepatocellular carcinoma, enabling the investigators to show that tumor progression correlates with tumor expansion in this tissue [32]. LCM has also been used to differentiate the morphologically distinct but interwoven compartments of B-cell lymphomas. Whereas DNA from whole tissue failed to reveal evidence for biclonality, an LCM-based study revealed multiple independent clonal rearrangements in tumors, suggesting distinct clonal origins [20]. In addition, the power of LCM is well suited for use in conjunction with immunostaining [19]. In identifying p53 point mutations, Tam and colleagues recently demonstrated that there is only a weak concordance between immunostaining and molecular analysis of whole tumors, presumably due to the fact that tumor staining is highly heterogeneous. When LCM was employed to isolate specific p53-stained tumor cells, the concordance of p53 mutation detection between immunostaining and molecular analysis improved fourfold [36]. Importantly, LCM has proven useful in concert with high-throughput molecular analyses, as Erlander and colleagues used LCM to procure individual neuronal subtypes from rodent brains and study gene expression patterns by cDNA microarrays [24].
In our laboratory, tissue microdissection was utilized to assist in the identification and cloning of the gene for multiple endocrine neoplasia type 1 by allowing procurement and allelic deletion analysis of multiple small neuroendocrine tumors from patients in affected kindreds $[8,14]$. Currently, we are using a tissue microdissection-based approach in an effort to begin elucidating the molecular events that underlie prostate cancer as a part of the Cancer Genome Anatomy Project (CGAP) of the National Cancer Institute [33, 34]. All of the data associated with CGAP are made immediately available to the research community via the Internet (http://www.ncbi.nlm.nih.gov//ncicgap/). Through molecular profiling of microdissected normal prostate tissue, prostatic intraepithelial neoplasia (PIN), and invasive carcinoma of the prostate (see Fig. 1), there exists a unique opportunity to examine the nature and sequence of genetic alterations that occur during tumor progression. Therefore, we constructed representative cDNA libraries from $12 \mathrm{mi}-$ crodissected prostate samples that included a spectrum of normal and neoplastic phenotypes [21]. The libraries were subjected to EST sequencing and the data analyzed by a variety of statistical tests. These data have been used for a number of studies including construction of a prostate epithelial unigene set, identification of prostate-unique genes, and comparison of gene expression profiles that occur during tumor progression [16].

Tissue microdissection also expands the opportunity for disease gene hunting. For example, prostate cancer shows a high rate of allelic loss on chromosome band $8 \mathrm{p} 21$. Thus, this region of the genome may contain a tumor suppressor gene (TSG) that is important in the development of prostate neoplasia. Since the use of tissue microdissection and PCR analysis of loss of heterozygosity allows for definitive scoring of allelic loss, we have been able to determine a minimal gene interval on chromosome band 8 p21 that is likely to harbor the responsible TSG [35]. Microdissection has also been critical in allowing us to examine allelic loss patterns in PIN, the putative precursor lesion of prostate cancer. PIN exists in the prostate as discrete microscopic foci generally found in association with tumor. Previous studies in our group showed that PIN exhibits a high level of allelic loss on chromosome band $8 \mathrm{p} 21$, and, in fact, the minimal gene interval in our recent study was defined by a case of PIN $[17,35]$.

Although the power of tissue microdissection has become quite clear in research involving the molecular analysis of nucleic acids, there is currently less data 

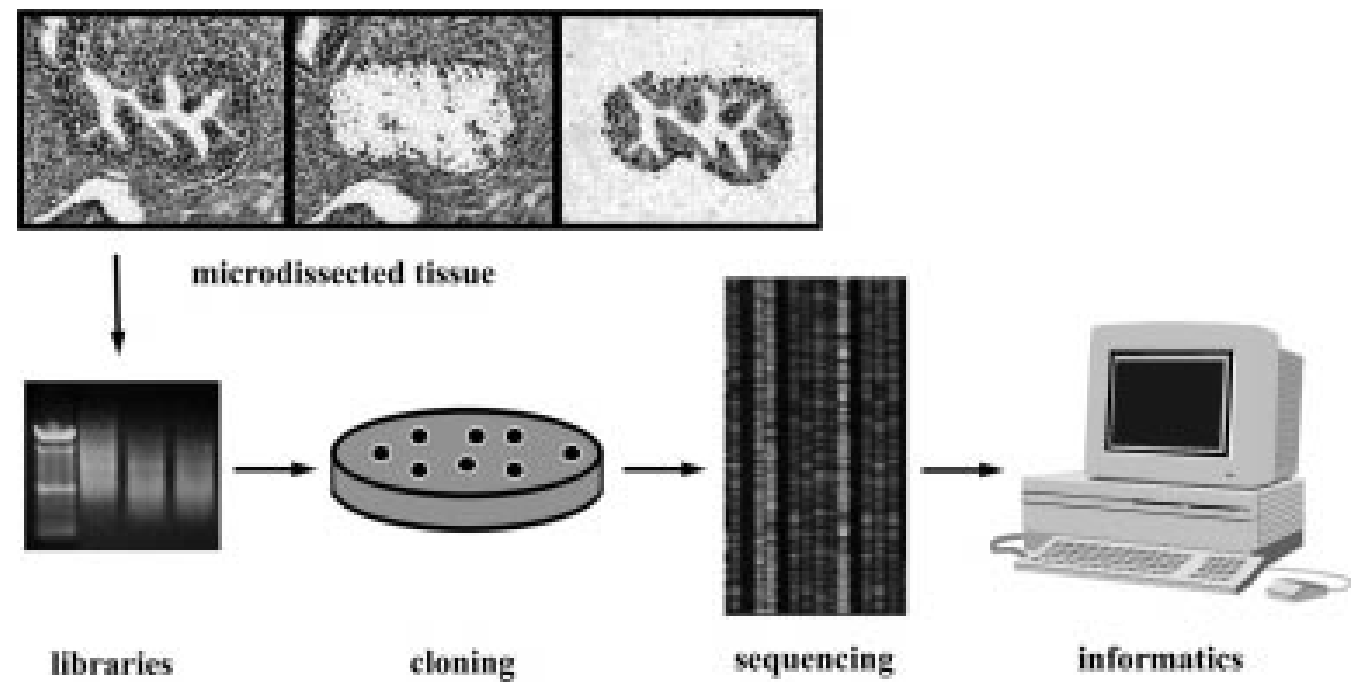

Fig. 1. Molecular profiling of LCM-derived prostate tissue. Following microdissection of normal epithelium, PIN (shown above), and invasive carcinoma of the prostate, RNA was isolated and subjected to RT-PCR. Linkers were attached to the double-stranded cDNA, which was then amplified by PCR to generate cDNA libraries. Libraries were cloned via UDG vectors and the clones subjected to sequencing. The sequence data was filtered and subsequently entered into dbEST. The flow of reagents and information essentially followed that initially designed by the I.M.A.G.E. consortium [23]. This approach allows for identification of transcripts specifically expressed in cells of a distinct origin and tumorigenic stage.

available regarding its efficacy in proteomics and the determination of protein profiles from microdissected samples. In one study, Banks and colleagues recently demonstrated that LCM-based analysis was useful in the study of protein patterns in the normal cervix [3]. In addition, our laboratory has been assessing the utility of LCM for studying protein profiles using three analysis methods: two-dimensional gel electrophoresis (2D-PAGE), surface enhanced laser desorption ionization (SELDI) and quantitative LCM [13,27,31]. Results to date indicate that proteomic studies of microdissected cell samples are a powerful method to examine protein alterations that occur during the evolution of a disease $[13,15,31]$. For example, initial 2DPAGE-based experiments comparing dissected normal prostate epithelium and patient-matched tumors of three cases demonstrated that $98 \%$ of the observed proteins were identical between the cell types. However, eight proteins were discovered that showed an identical change (up- or down-regulation) in each tumor. Determination of the identity of these proteins is underway. Surface Enhanced Laser Desorption Ionization (SELDI) is a new technology that utilizes matrixassisted laser desorption and time-of-flight analysis to study proteins [22]. Protein profiles can be generated from lysates of 1500 LCM-procured epithelial cells and proteins as small as $2,000 \mathrm{kD}$ can be reliably detected. Applied to prostate cancer progression, we have found that SELDI protein profiles differ reproducibly among benign and malignant prostate epithelial cells [27]. Quantitative LCM is a newly developed method that permits determination of protein levels from microdissected cell samples using an automated sandwich chemiluminescent immunoassay. Initial studies have demonstrated the utility of this approach by precisely measuring prostate specific antigen (PSA) from microdissected prostate cells [31].

Lastly, our laboratory is currently developing two new strategies for molecular profiling of human tumorigenesis. The first is a novel analytical method that utilizes a layered array of capture membranes to perform high-throughput DNA, mRNA, or protein measurements from biological samples [18]. The method works by transferring cell or tissue samples through a series of individual capture layers, each linked to a separate antibody or DNA sequence. As the samples traverse the membrane set, each targeted protein or mRNA is specifically captured by the layer containing its antibody or complementary DNA sequence. The two-dimensional relationship of the cell populations is maintained during the transfer process, thereby producing a molecular profile of each cell type present. The second new strategy is a three-dimensional approach to the study of prostate cancer [9]. As shown in Fig. 2, this approach allows investigators to query gene expression and proteomic data and view these data in 


\section{Panel A}

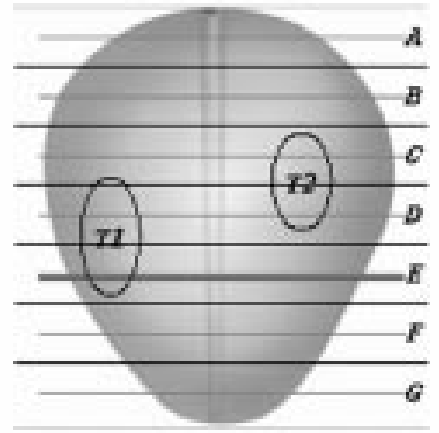

\section{Panel B}

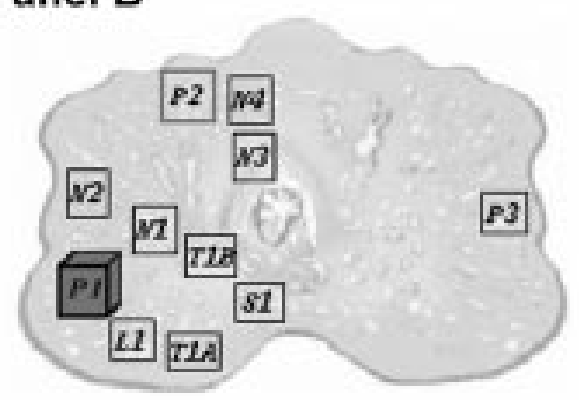

\section{Panel C}

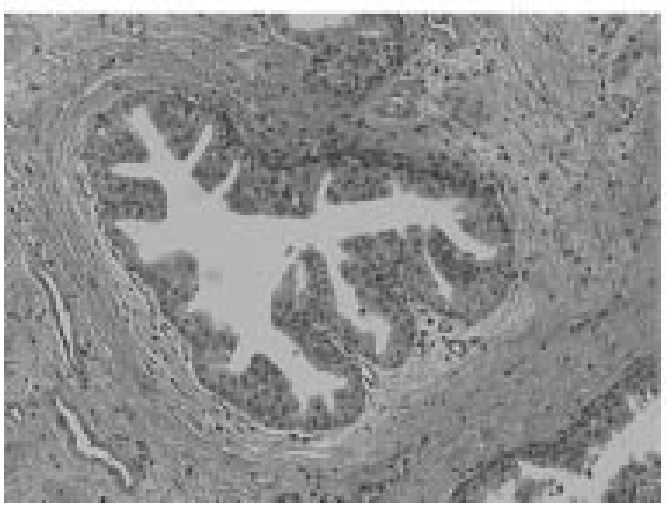

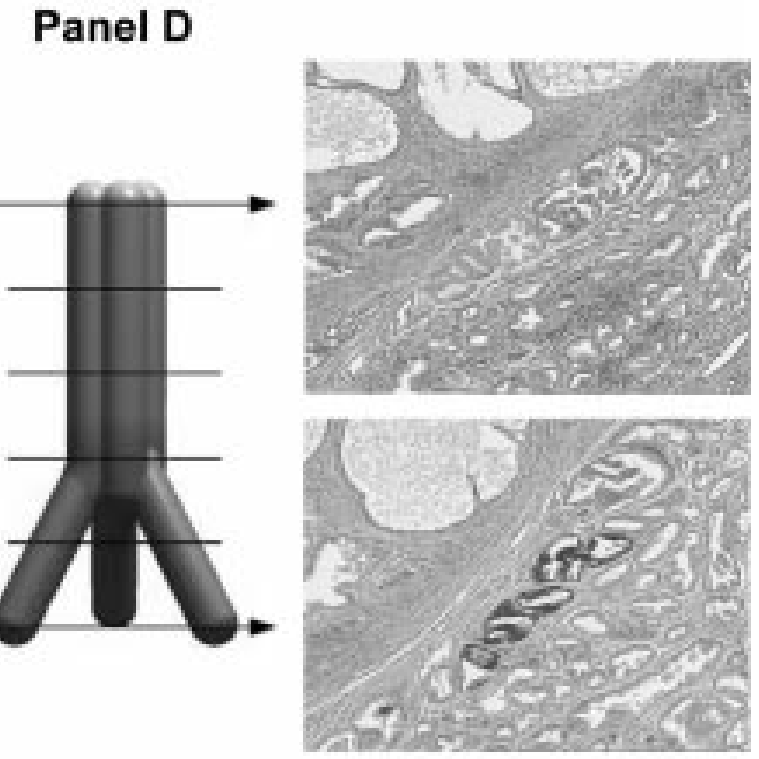

\section{Panel E}

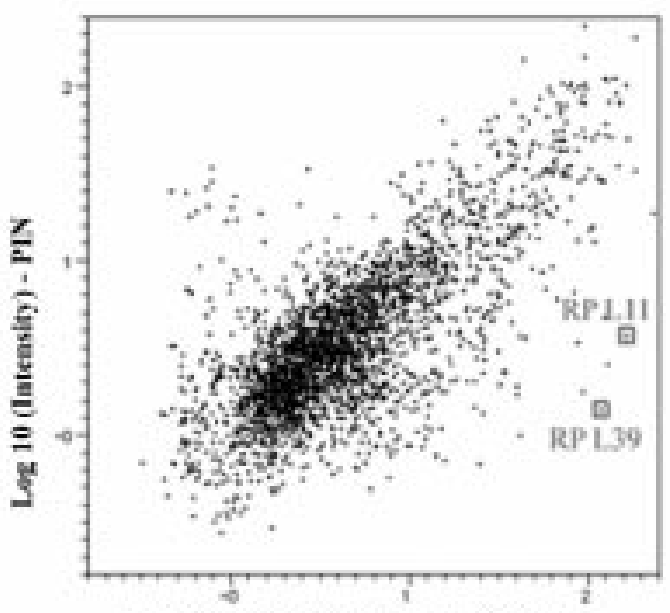

Log 10 (Inteasity) - Prostate Cancer

Fig. 2. Three-dimensional molecular analysis approach to the study of prostate cancer. Panel A shows an overview of a whole prostate showing the number, extent and anatomic locations of tumors at various levels of the gland. In this patient, the prostate has two tumors present, T1 and T2. The transverse view of block E (panel B) demonstrates there are two areas of high-grade cancer, T1A and T1B. In addition, there are three areas of prostatic intraepithelial neoplasia (PIN), one near the tumor (P1) and two distant (P2 and P3). There is also an area of low-grade cancer with nearby lymphocytes (L1) and abundant histologically normal epithelium (N1-4). The hyperlinked box (P2) links to a representative hematoxylin and eosin stained, high-resolution image of the region of study (panel C). The hyperlinked cube links to a serial sectioning study that has been performed on this microstructure (panel D). Panel E shows an example of a global gene expression study that compared PIN and prostate cancer using sequence analysis of cDNA libraries. Several ribosomal protein genes were expressed at significantly higher levels in cancer than PIN, including RPL11 and RPL39. 
concert with the relevant histopathology. A 3D reconstruction approach allows both the physical and molecular relationship of all entities to be determined, e.g., which dysplastic lesions are developing into tumor and how the gene expression profiles change as this process unfolds. A second advantage of the 3D analytical approach is the opportunity to study the complete spectrum of tumor progression in proper context. Ultimately, the goal of this approach is a better understanding of prostate tumorigenesis at a molecular level that leads to improved diagnosis and treatment for patients, and the ability to generate data from microdissected cell samples is an integral and invaluable part of this endeavor

\section{References}

[1] A. Abbott, DNA chips intensify the sequence search, Nature 379(6564) (1996), 392.

[2] N.L. Anderson and N.G. Anderson, Proteome and proteomics: new technologies, new concepts, and new words, Electrophoresis 19 (1998), 1853-1861.

[3] R.E. Banks, M.J. Dunn, M.A. Forbes, A. Stanley, D. Pappin, T. Naven, M. Gough, P. Harnden and P.J. Selby, The potential use of laser capture microdissection to selectively obtain distinct populations of cells for proteomic analysis - preliminary findings, Electrophoresis 20(4-5) (1999), 689-700.

[4] I. Becker, K. Becker, M.H. Rohrl and H. Hofler, Laser-assisted preparation of single cells from stained histological slides for gene analysis, Histochem. Cell Biol. 108 (1997), 447-451.

[5] M. Bohm, I. Wieland, K. Schutze and H. Rubben, Non-contact laser microdissection of membrane-mounted native tissue, Am. J. Pathol. 151 (1997), 63-67.

[6] R.F. Bonner, M.R. Emmert-Buck, K.A. Cole, T. Pohida, R.F. Chuaqui and S.R.L. Goldstein, and L.A. Liotta, Laser capture microdissection: molecular analysis of tissue, Science $\mathbf{2 7 8}$ (1997), 1481-1483.

[7] J.E. Celis, M. Ostergaard, N.A. Jensen, I. Gromova, H.H. Rasmussen and P. Gromov, Human and mouse proteomic databases: novel resources in the protein universe, FEBS Lett. 430 (1998), 64-72.

[8] S.C. Chandrasekharappa, S.C. Guru, P. Manickam, S.E. Olufemi, F.S. Collins, M.R. Emmert-Buck, L.V. Debelenko, Z. Zhuang, I.A. Lubensky, L.A. Liotta, J.S. Crabtree, Y. Wang, B.A. Roe, J. Weisemann, M.S. Boguski, S.K. Agarwal, M.B. Kester, Y.S.H. Kim, C.Q. Dong, A.M. Spiegel, A.L. Burns and S.J. Marx, Positional cloning of the gene for multiple endocrine neoplasia-type 1, Science 276(5311) (1997), 404-407.

[9] K.A. Cole, D.B. Krizman and M.R. Emmert-Buck, The genetics of cancer - a 3D model, Nature Genet. 21(1 Suppl.) (1999), $38-41$.

[10] J. DeRisi, L. Penland, P.O. Brown, M.L. Bittner, P.S. Meltzer, M. Ray, Y. Chen, Y.A. Su and J.M. Trent, Use of a cDNA microarray to analyse gene expression patterns in human cancer, Nature Genet. 14 (1996), 457-460.
[11] A. Dove, Proteomics: translating genomics into products?, Nat. Biotechnol. 17 (1999), 233-236.

[12] M.R. Emmert-Buck, R.F. Bonner, P.D. Smith, R.F. Chuaqui, S.R. Goldstein, Z. Zhuang, R.A. Weiss and L.A. Liotta, Laser capture microdissection, Science 274 (1996), 998-1001.

[13] M.R. Emmert-Buck, J.W. Gillespie, C.P. Pawletz, D.K. Ornstein, V. Basrur, E. Appella, Q.-H. Wang, J. Huang, P. Taylor and E.F. Petricoin, III, A strategic approach for proteomic analysis of human tumors, Mol. Carcinog. 27 (2000), 1-8.

[14] M.R. Emmert-Buck, I.A. Lubensky, Q. Dong, P. Manickam, S.C. Guru, M.B. Kester, S.E. Olufemi, S. Agarwal, A.L. Burns, A.M. Spiegel, F.S. Collins, S.J. Marx, Z. Zhuang, L.A. Liotta, S.C. Chandrasekharappa and L.V. Debelenko, Localization of the multiple endocrine neoplasia type I (MEN1) gene based on tumor loss of heterozygosity analysis, Cancer Res. 57 (1997), 1855-1858.

[15] M.R. Emmert-Buck, M.J. Roth, Z. Zhuang, E. Campo, J. Rozhin, S.B. F, L.A. Liotta and W.G. Stetler-Stevenson, Increased gelatinase A (MMP-2) and cathepsin B activity in invasive tumor regions of human colon cancer samples, Am. J. Pathol. 145 (1994), 1285-1290.

[16] M.R. Emmert-Buck, R.L. Strausberg, D.B. Krizman, M.F. Bonaldo, R.F. Bonner, D.G. Bostwick, M.R. Brown, K.H. Buetow, R. Chuaqui, K.A. Cole, P.F. Duray, C.R. Englert, J.W. Gillespie, S. Greenhut, G. Grouse, L.W. Hillier, K.S. Katz, R.D. Klausner, V. Kuznetzov, A.E. Lash, G. Lennon, W.M. Linehan, L.A. Liotta, M.A. Marra, P.J. Munson, D.K. Ornstein, V. Prabhu, C. Prange, G.D. Schuler, M.B. Soares, C.M. Tolstoshev, C.D. Vocke and R.H. Waterston, Molecular profiling of clinical tissue specimens: feasibility and applications, Am. J. Pathol. (2000), in press.

[17] M.R. Emmert-Buck, C.D. Vocke, R.O. Pozzatti, P.H. Duray, S.B. Jennings, C.D. Florence, Z. Zhuang, D.G. Bostwick, L.A. Liotta and W.M. Linehan, Allelic loss on chromosome 8p12-21 in microdissected prostatic intraepithelial neoplasia (PIN), Cancer Res. 55(14) (1995), 2959-2962.

[18] C.R. Englert, G.V. Baibakov and M.R. Emmert-Buck, Layered expression scanning: rapid molecular profiling of tumor samples, Cancer Res. 60 (2000), 1526-1530.

[19] F. Fend, M.R. Emmert-Buck, R. Chuaqui, K. Cole, J. Lee, L.A. Liotta and M. Raffeld, Immuno-LCM: laser capture microdissection of immunostained frozen sections for mRNA analysis, Am. J. Pathol. 154(1) (1999), 61-66.

[20] F. Fend, L. Quintanilla-Martinez, S. Kumar, M.W. Beaty, L. Blum, L. Sorbara, E.S. Jaffe and M. Raffeld, Composite lowgrade B-cell lymphomas with two immunophenotypically distinct cell populations are true biclonal lymphomas. A molecular analysis using laser capture microdissection, Am. J. Pathol. 154(6) (1999), 1857-1866.

[21] D.B. Krizman, R.F. Chuaqui, P.S. Meltzer, J.M. Trent, P.H. Duray, W.M. Linehan, L.A. Liotta and M.R. Emmert-Buck, Construction of a representative cDNA library from prostatic intraepithelial neoplasia (PIN), Cancer Res. 56(23) (1996), 5380-5383.

[22] H. Kuwata, T.T. Yip, C.L. Yip, M. Tomita and T.W. Hutchens, Bactericidal domain of lactoferrin: detection, quantitation, and characterization of lactoferricin in serum by SELDI affinity mass spectrometry, Biochem. Biophys. Res. Commun. 245 (1998), 764-773. 
[23] G. Lennon, C. Auffray, M. Polymeropolous and M.B. Soares, The I.M.A.G.E. Consortium: an integrated molecular analysis of genomes and their expression, Genomics 33 (1996), 151152.

[24] L. Luo, R.C. Salunga, H. Guo, A. Bittner, K.C. Joy, J.E. Galindo, H. Xiao, K.E. Rogers, J.S. Wan, M.R. Jackson and M.G. Erlander, Gene expression profiles of laser-captured adjacent neuronal subtypes, Nature Med. 5 (1999), 112-122.

[25] C.A. Moskaluk and S.E. Kern, Microdissection and polymerase chain reaction amplification of genomic DNA from histological tissue sections, Am. J. Pathol. 150 (1997), 1547-1552.

[26] R. Nowak, Entering the postgenome era, Science 270 (1995), 368-371.

[27] C.P. Pawletz, D. Ornstein, J.W. Gillespie, K.A. Cole, N.L. Simone, Y. Yip, T.W. Hutchens, M.R. Emmert-Buck, L.A. Liotta and E.F. Petricoin, Tissue proteomics at the microscale: a novel approach to the study of disease progression, Drug Devel. Res. (2000), in press.

[28] G. Ramsay, DNA chips: state of the art, Nat. Biotechnol. 16 (1998), 40-44.

[29] M. Schena, R.A. Heller, T.P. Theriault, K. Konrad, E. Lachenmeier and R.W. Davis, Microarrays: biotechnology's discovery platform for functional genomics, Trends Biotechnol. 16 (1998), 301-306.

[30] D. Shibata, D. Hawes, Z.H. Li, A.M. Hernandez, C.H. Spruck and P.W. Nichols, Specific genetic analysis of microscopic tissue after selective ultraviolet radiation fractionation and the polymerase chain reaction, Am. J. Pathol. 141(3) (1992), 539543.

[31] N.L. Simone, A.T. Remaley, L. Charboneau, E.F. Petricoin, III, J.W. Glickman, M.R. Emmert-Buck, T.A. Fleisher and L.A. Liotta, Sensitive immunoassay of tissue cell proteins procured by laser capture microdissection, Am. J. Pathol. 156 (2000), 445452.

[32] Y. Sirivatanauksorn, V. Sirivatanauksorn, S. Bhattacharya, B.R. Davidson, A.P. Dhillon, A.K. Kakkar, R.C. Williamson and N.R. Lemione, Evolution of genetic abnormalities in hepatocellular carcinomas demonstrated by DNA fingerprinting, $J$. Pathol. 189(3) (1999), 344-350.

[33] R.L. Strausberg, D.C. A and K.R. D, New opportunities for uncovering the molecular basis of cancer, Nature Genet. 15 (1997), 415-416.

[34] R.L. Strausberg, K.H. Buetow, M.R. Emmert-Buck and R.D. Klausner, The Cancer Genome Anatomy Project: Building an annotated gene index, Trends Genet. 16 (2000), 103106.

[35] J.I. Swalwell, C.D. Vocke, L. Grouse, Y. Yang, T. Thomas Ried, S.H. Myers, J.W. Gillespie, E. Konieczynski, J. Lee, P.H. Duray, D.G. Bostwick, W.M. Linehan and M.R. EmmertBuck, Determination of a minimal tumor suppressor gene interval on chromosome band 8p21 in sporadic prostate cancer, Manuscript submitted.

[36] A.S. Tam, J.F. Foley, T.R. Devereux, R.R. Maronpot and T.E. Massey, High frequency and heterogeneous distribution of p53 mutations in aflatoxin B1-induced mouse lung tumors, Cancer Res. 58(15) (1999), 3634-3640.

[37] V. Velculescu, L. Zhang, B. Vogelstein and K. Kinzler, Serial analysis of gene expression, Science 270 (1995), 484-487.

[38] L. Zhang, W. Zhou, V.E. Velculescu, S.E. Kern, R.H. Hruban, S.R. Hamilton, B. Vogelstein and K.W. Kinzler, Gene expression profiles in normal and cancer cells, Science 276(5316) (1997), 1268-1272. 


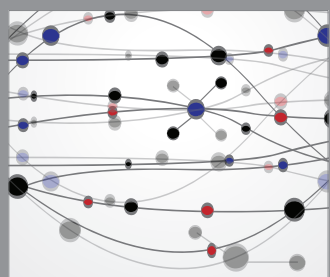

The Scientific World Journal
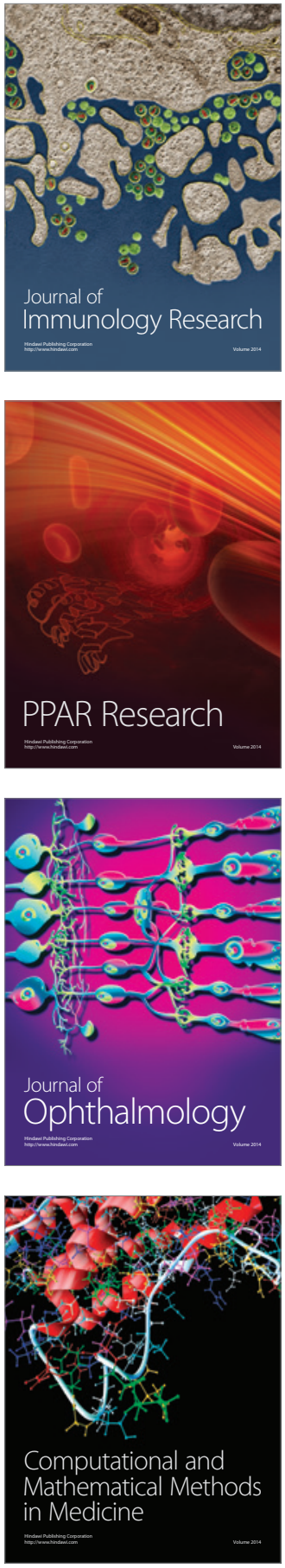

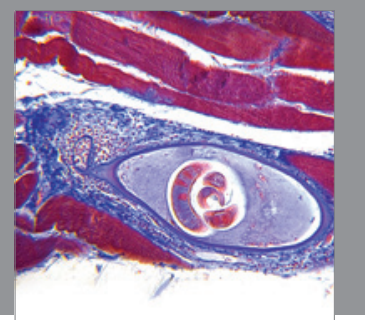

Gastroenterology

Research and Practice
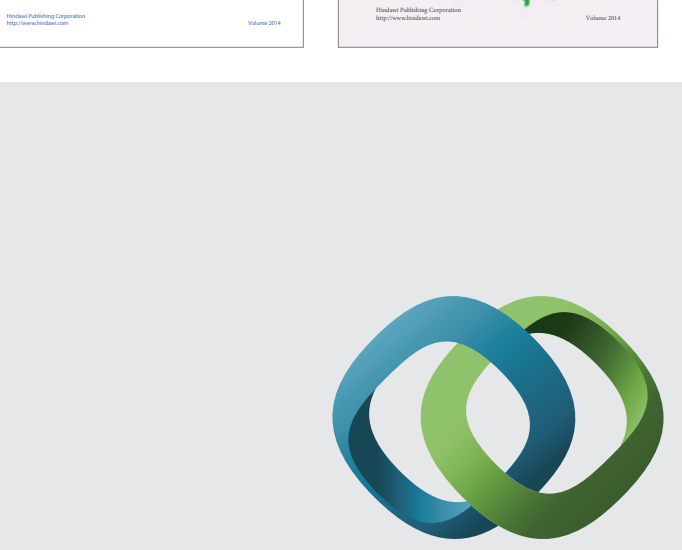

\section{Hindawi}

Submit your manuscripts at

http://www.hindawi.com
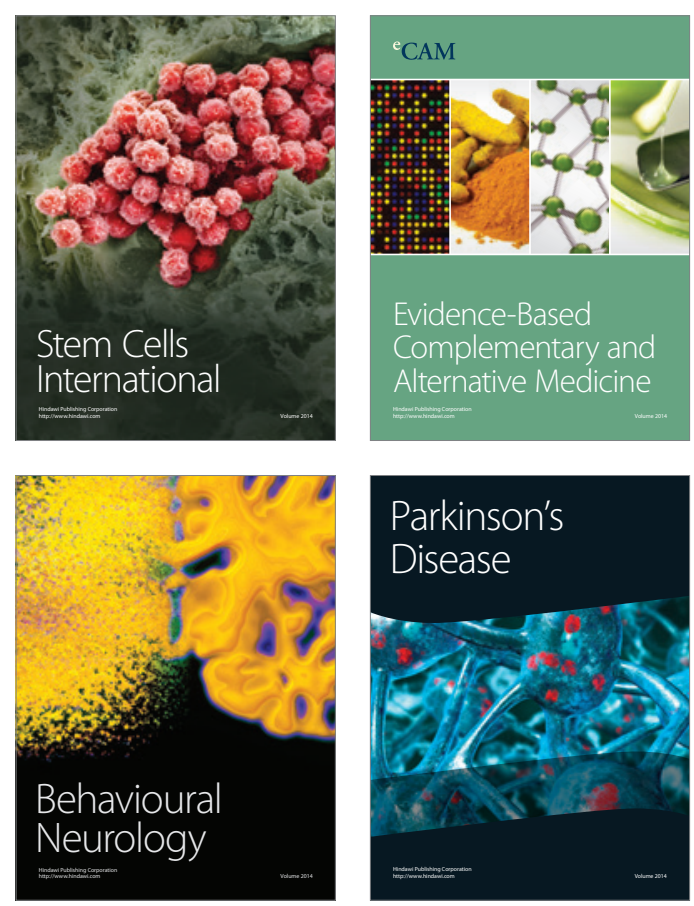

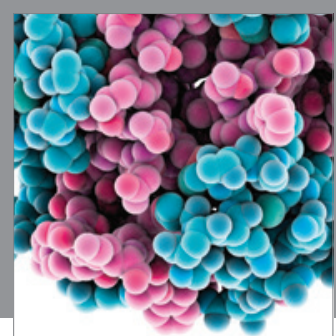

Journal of
Diabetes Research

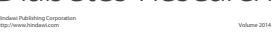

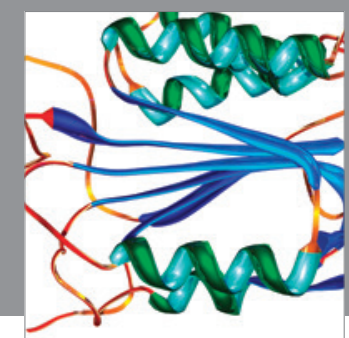

Disease Markers
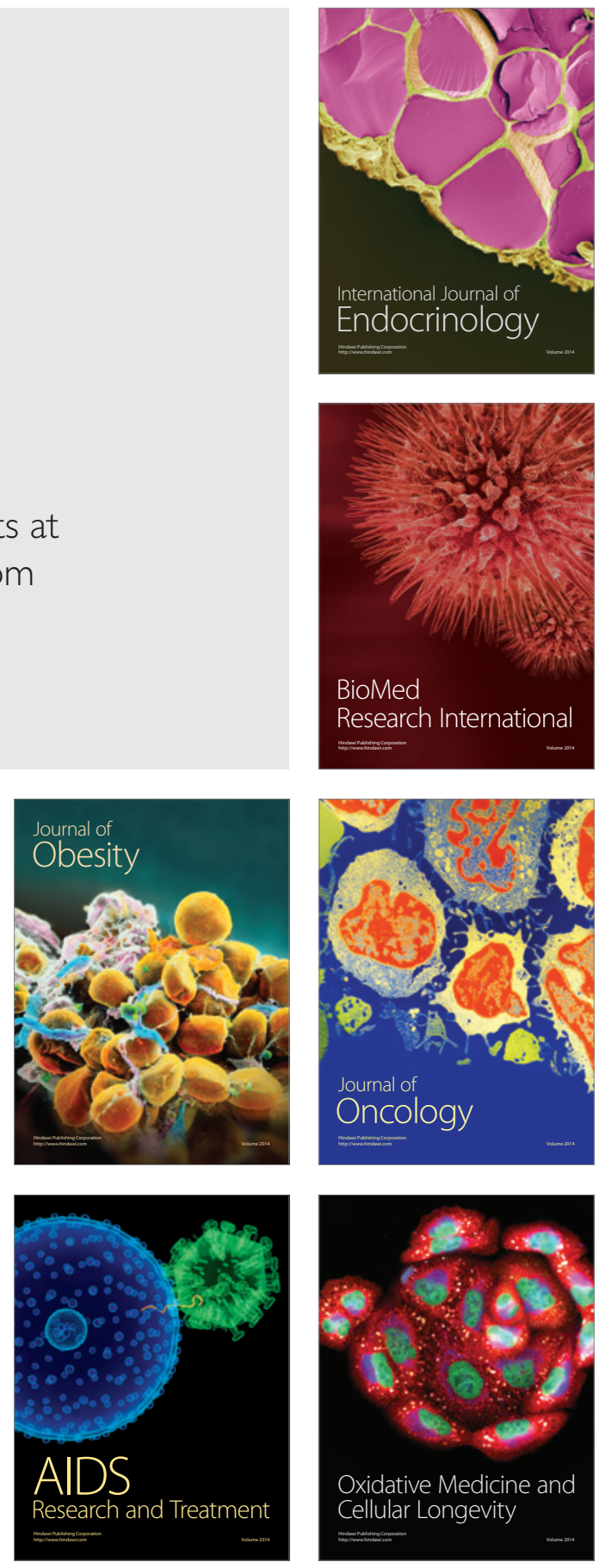